\title{
凤眼莲等水生植物对含银废水的净化 与银回收研究*
}

\author{
戴全裕 陈源高 周万平 \\ (中国科学院南京地理与湖泊研究所,南京 210008) \\ 郭耀基 张聍 皮宇 \\ (无锡电影胶片厂，无氛214165）
}

\section{关链词 凤眼莲、银、净化、回收}

目前, 影业系统感光材料厂和各种胶片洗印厂仅能处理较高浓度的含银废水, 而对低于 $2-3 \mathrm{mg} \mathrm{Ag} / \mathrm{L}$ 的废水就难于处理了, 因而银的流失量仍然比较严重. 据中国人民银行总行统 计, 我国每年应回收白银 $90 t$, 而实际仅回收 $20 t$, 流失 $70 t$, 价值达 6300 万元 ${ }^{\omega}$. 这不仅是一项 巨大的经济损失,还会给环境带来严重的危害. 针对上述情况, 我们于 1987-1989 年开展了利 用凤眼莲等水生植物对含银废水的净化与银的回收研究, 经过三年的努力, 终于突破了低浓度 含银废水净化和微量银回收的技术难题, 成功地从净化含银废水的水生植物残体中提情出了 白银, 提出了植物残体处理的有效途径, 并较深地揭示了水生植物对废水中银净化与富集的机 理. 该法经在无锡电影胶片厂两年的生产性应用考验, 证明是行之有效的, 其对银的去除率达 90-98.6\%, 水质净化效果良好, 取代了该厂原来的活性炭吸附和臭氧篻化的三级处理, 年节 约运转费用达 12.5 万元. 这不仅在学术上有重要意义, 而且在实践上为含银废水净化与资源 化司出了一条新路.

\section{一、实验材料与方法}

1. 生物材料的选择 过去对废水净化仅局限于少数几种水生植物, 且缺乏对耐寒水生 植物的选用. 本项研究经过对 29 种不同生活型的(浮叶、沉水、飘浮、挺水)水生植物篮选和培 育, 结果表明: 凤眼莲(Eichhornia crassipes)、水䔨菜 (Ipomoea aquatica)、水芹菜 (Oenanthe javanica) 等是净化含银废水的优良种类.

2. 试验用含银废水种类 不同的影业系统工厂, 其含银废水的性质是不同的. 为了适 应各种含银废水的净化需要, 本项研究选用了三种废水试验, 即以 $\mathrm{AgBr}$ 为主的胶片废水, 以 $\left[\mathrm{Ag}\left(\mathrm{S}_{2} \mathrm{O}_{3}\right)_{2}\right]^{3-}$ 为主的洗印废水 (均由无锡电影胶片厂提供)和其它工厂的 $\mathrm{AgNO}_{3}$ 废水.

3. 方法 实验共分四个阶段进行:（1)室内静态试验;(2)工厂动态模拟实验; (3)生产 性应用试验; (4)植物残体的处理和白银的提炼.

动态模拟试验: 选用一条 $45 \times 0.36 \times 0.44 \mathrm{~m}$ 的水泥沟中进行. 全沟分为三级, 每级长 $15 \mathrm{~m}$

本文 1990 年 7 月 13 日收到. 1990 年 9 月 26 日收到修改稿.

- 国家自然科学基金资助项目. 


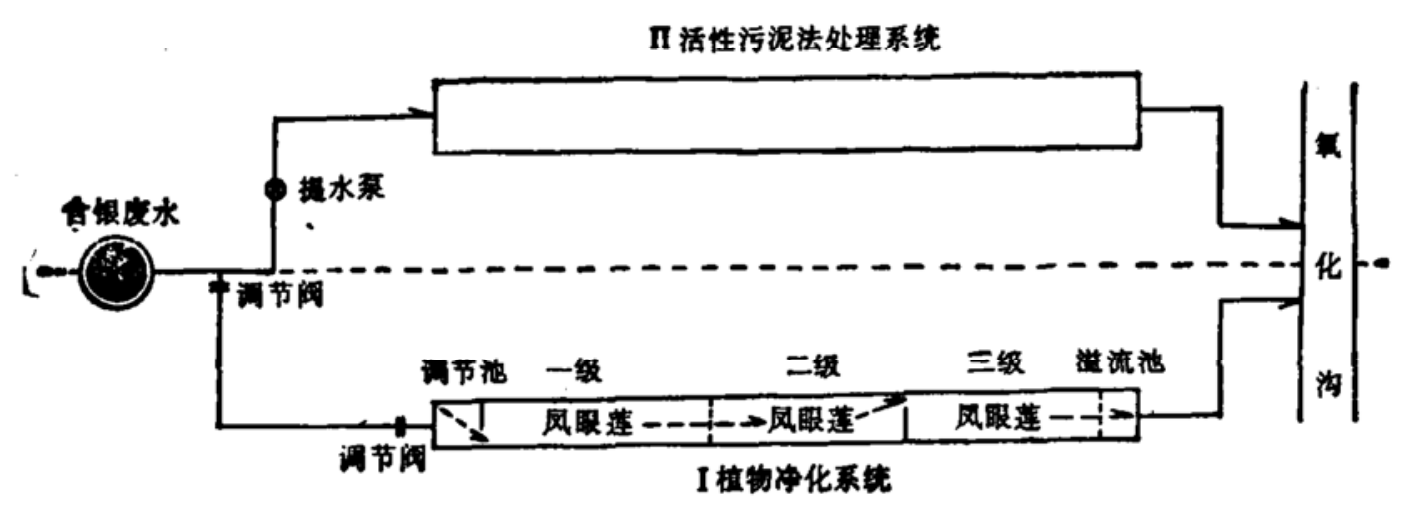

图 1 植物净化动态模似试验流程图

$\longrightarrow$ 水流方向

(同时作空白,不放水生植物), 见图 1 .

生产性应用实验: 选用无锡胶片厂活性污泥法沉淀池和羍化渠中进行. 沉淀池总水面积 为 $300 \mathrm{~m}^{2}$, 篻化渠全长 $99.6 \mathrm{~m}$, 平均宽 $4.52 \mathrm{~m}$, 水深 $0.5 \mathrm{~m}$, 有效净化水面积为 $450.2 \mathrm{~m}^{2}$ (见图 2 ).

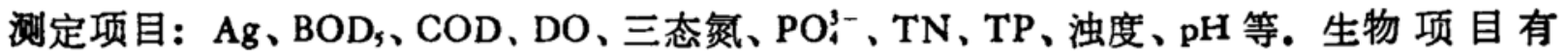
薄类、浮游动物、底栖生物、微生物等.

\section{二、结果与讨论}

1. 银离子对水生㨁物的伤害问值 摸清银离子对水生植物的伤害阈值是该项研究的基 础性工作. 根据银离子对水生植物伤害的叶面积百分比. 叶绿素含量变化以及生长状况, 得出 在温度 $25-30^{\circ} \mathrm{C}$ 条件下凤眼莲的伤害阈值: $\mathrm{AgBr}$ 为 $20 \mathrm{ppm} \times 48 \mathrm{~h} ;\left[\mathrm{Ag}\left(\mathrm{S}_{2} \mathrm{O}_{3}\right)_{2}\right]^{3-}$ 为 $16 \mathrm{ppm} \times$ $24 \mathrm{~h} 、 8 \mathrm{ppm} \times 48 \mathrm{~h} 、 4 \mathrm{ppm} \times 72 \mathrm{~h} ; \mathrm{AgNO}_{3}$ 为 $8 \mathrm{ppm} \times 24 \mathrm{~h}$ 或 $2 \mathrm{ppm} \times 72 \mathrm{~h}$. 未出现伤害的临 界剂量: $\mathrm{AgBr}$ 为 $2 \mathrm{ppm} \times 120 \mathrm{~h} ;\left[\mathrm{Ag}\left(\mathrm{S}_{2} \mathrm{O}_{3}\right)_{2}\right]^{3-}$ 为 $2 \mathrm{ppm} \times 120 \mathrm{~h}$ 和 $\mathrm{AgNO}_{3}$ 为 $1.0 \mathrm{ppm} \times$ $120 \mathrm{~h}$. 水䔨菜未见伤害症状的临界剂量: $\left[\mathrm{Ag}\left(\mathrm{S}_{2} \mathrm{O}_{3}\right)_{2}\right]^{3-}$ 为 $1.0 \mathrm{ppm} \times 120 \mathrm{~h} ; \mathrm{AgNO}_{3}$ 为 $0.5 \mathrm{ppm}$ $\times 120 \mathrm{~h}$. 不同形态的银对水生植物的毒性为 $\mathrm{AgNO}_{3}>\left[\mathrm{Ag}\left(\mathrm{S}_{2} \mathrm{O}_{3}\right)^{2}\right]^{3-}>\mathrm{AgBr}$.

\section{2. 水生植物对含银废水的净化效果}

（1）凤眼莲对胶片废水净化的动态模拟试验. 胶片废水的主要成分是 $\mathrm{AgBr}$. 为了比较 不同方法对含银废水处理的效果, 本动态模拟试验采取与该厂活性污泥法同步进行, 并取同一 污染源（见图 1). 试验结果表明: 水生植物净化法对含银废水处理的主要指标均已达到该厂 活性污泥法, 甚至超过活性污泥法. 如对银的平均去除率达 $98.6 \%, \mathrm{BOD}_{5}$ 去除率 $91 \%$, 浊度 去除率 $92.9 \%$, 而同期的活性污泥法则分别为 $94.1 、 92.9$ 和 $88.4 \%$ 。同时,活性污泥法需要较 离的成本,而水生植物净化法仅需其成本的 $1 / 3-1 / 4$.

（2）水潍菜对洗印废水的净化率. 水䔨菜的动态模拟实验, 采取进 水银浓度 ( $\left[\mathrm{Ag}\left(\mathrm{S}_{2}\right.\right.$ $\left.\left.\mathrm{O}_{3}\right)_{2}\right]^{3-}$ ) 为 $1.0 \mathrm{ppm}$, 污水停留时间为 $48 、 72$ 和 $96 \mathrm{~h}$, 其对银的去除率分别达 $83.4 、 89.7$ 和 $92.7 \%$, 而无水生植物时, 其自然去除率 (对照值)为 $30.1 \%$. 这也说明, 水生植物对废水中银 有明显的净化作用.

（3）水芹菜等耐寒水生植物对含银废水的净化率见表 1 . 通过静态和动态试验结果, 证 明寒冷季节(2-5 月) 可以应用水芹菜来净化含银废水(另文发表).

（4）生产性应用实例. 在大最室内外试检的基础上, 根据图 2 装置在无锡电影胶片厂进 
表 1 耐低温水生植物净化率与温度的关系*

\begin{tabular}{|c|c|c|c|c|c|}
\hline \multirow{2}{*}{ 植物名称 } & \multirow{2}{*}{ 气温 $\left({ }^{\circ} \mathrm{C}\right)$} & \multirow{2}{*}{ 水温 $\left.{ }^{\circ} \mathrm{C}\right)$} & \multicolumn{3}{|c|}{ 净化率(\%) } \\
\hline & & & $12 \mathrm{~h}$ & $48 \mathrm{~h}$ & $72 \mathrm{~b}$ \\
\hline 水年 (Oenanthe javanica) & $9-10$ & $10-11$ & 82.96 & 90.91 & 90.91 \\
\hline 荡 (Apium graveolens) & $9-10$ & $10-11$ & 76.15 & 89.21 & 89.78 \\
\hline 淔草 (Potamogeton crispus) & $9-10$ & $10-11$ & 89.21 & 96.59 & 98.86 \\
\hline
\end{tabular}

- 起始 $\mathrm{Ag}^{+}$浓度为 $2 \mathrm{ppm} ; 12 、 48,72 \mathrm{~h}$ 为停留时间.

行了水生植物对含银废水净化生产性应用研究, 其结果为: 当进水银浓度为 40.3-207.8pph, 平 均 97.4ppb, 污水停留时间 49h 时, 其出水银浓度为 $0-6.0 \mathrm{ppb}$, 平均为 $1.8 \mathrm{ppb}$, 净化率达 94.3$100 \%$, 出水水质清彻. 由于水生植物对含银废水净化效果显著, 因而该厂决定采用该法取代 了原来的活性炭吸附和臭氧氧化的三级处理,节约年运转费用 12.5 万元.

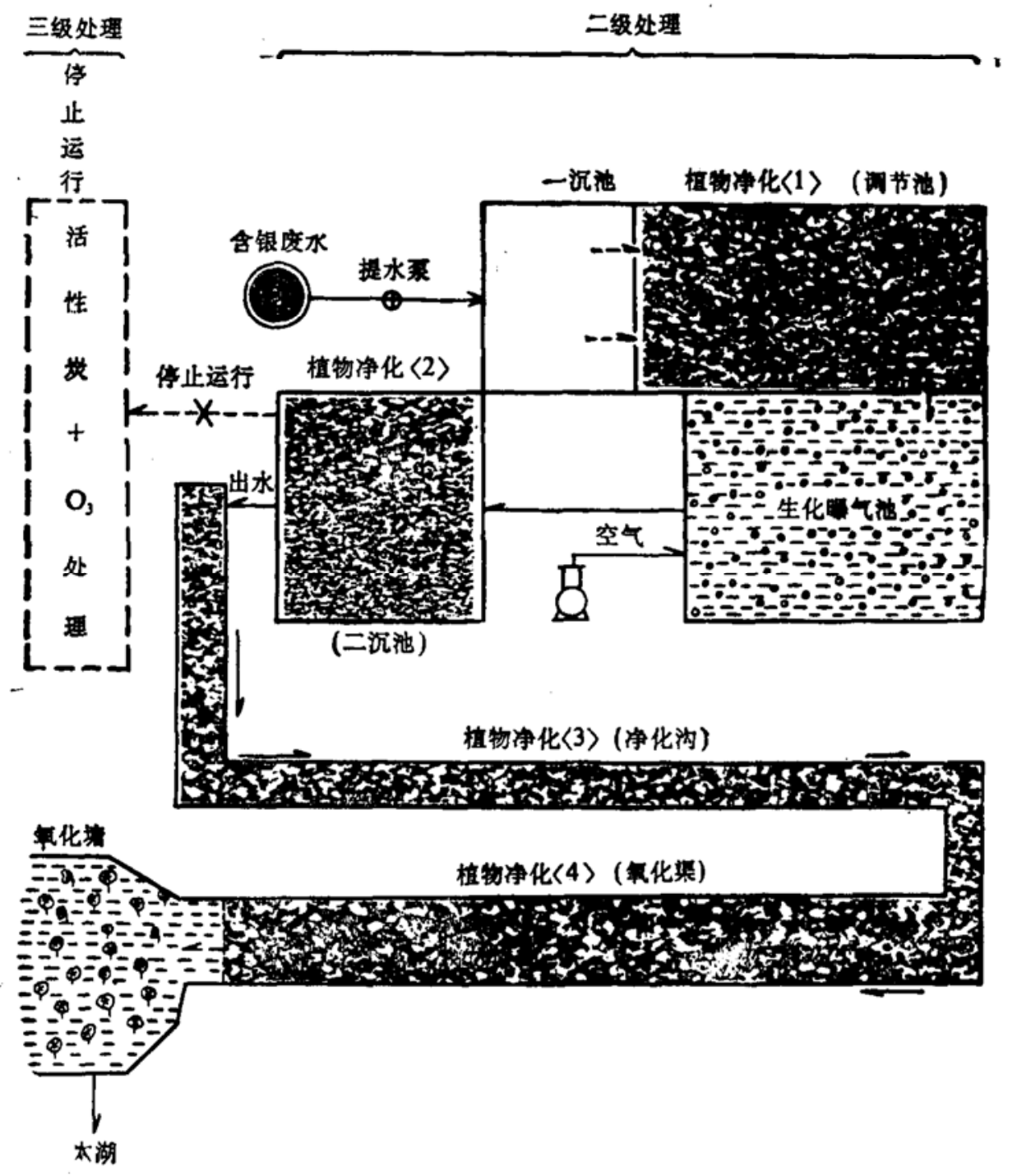

固 2 水生高等植物对含银废水净化与资源化生态工程流程图(模式之一) 
4. 水生接物对废水中银的亡策系数、柱物棵体处理及其银的回收 据 Wolverton 报道 凤眼莲根部对银的富集量为 $113 \mathrm{ppm}(\mathrm{DM})^{[2,3]}$. 经本文试验和采样分析, 当废水中银浓度为 $80-160 \mathrm{ppb}$, 平均为 $120 \mathrm{ppb}$ 时 (净化时间 30 天左右), 其叶部的含银量达 443.6ppm, 叶柄含银 年为 $311.7 \mathrm{ppm}$, 根部含银量为 $12251 \mathrm{ppm}(\mathrm{DM})$, 富集系数分别为 $3613 、 2598 、 102094$, 其中根 部银的富集量比国外高 98.5 倍. 若折合成植物灰分, 则叶部含银量为 $0.221 \%$, 富集系数 18416 , 叶柄含银量 $0.221 \%$, 富集系数 18416 , 根部含银量为 $4.125 \%$, 富集系数高达 343756 . 这说明, 凤眼莲对废水中银具有“惊人”的富集系数,这是文献中未见报道的.

白银的回收与植物残体的合理处理,实际上是一个问题的两个方面. 其主要方法是: (1) 将植物残体直接打捞、值干、灰化、 $\mathrm{HNO}_{3}$ 提取, 氯化法沉淀直至火法冶炼(碳酸钠十硼砧) $\rightarrow$ 出 银; (2)先将植物残体制造沼气, 尔后由残渣、残液经焚烧或化学沉淀按上述方案处理 $\rightarrow$ 出银. 这样既可充分利用植物的化学能, 又可得到白银, 减少污染; (3)将植物残体全部集中, 唒干, 最 后由贵稀金属提炼厂专门处理。本文在试验期间已采用 (1)、(3) 两种方法成功地从净化含银 废水的水生植物残体中提炼和回收出白银 $561.7 \mathrm{~g}$ (纯度 $99 \%$ 以上), 这在国际上还属首次(见 图3).

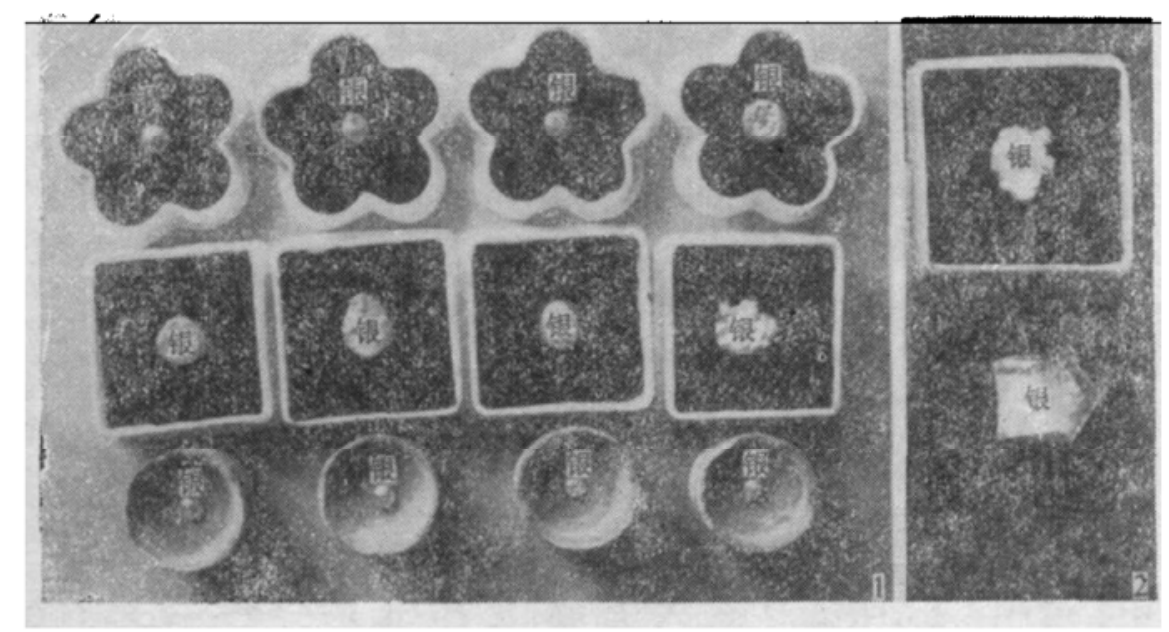

图 3 从净化含银废水的风眼莲残体中提炼出来的白银 1.由笑验室提炼出来的; 又由国营上海贵椅金提炼厂提炼出来的

致谢: 叶斌、醜云同志负费清绘.

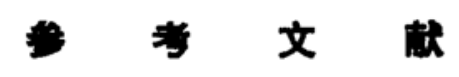

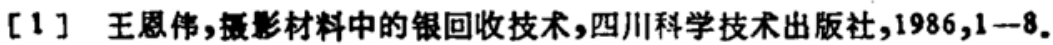

[2] Wolverton. B.C. et el., NASA, TM-X-72722, 1975.

[ 3 ] Wolverton, B.C. et al., NASA, TM-X-72727, 1975. 